\title{
Del pajarístico al lenguaje de los pájaros*
}

From "pajarístico" to the language of the birds

Felipe Cussen

Universidad Diego Portales. Santiago, Chile.

felipe.cussen@udp.cl

\section{RESUMEN}

En este artículo rastreo algunas de las fuentes enunciadas por Juan Luis Martínez en dos textos de La nueva novela, y los relaciono con otros músicos y poetas que comparten la obsesión por los pájaros. A partir de allí analizo el tópico del lenguaje del paraíso, que refleja el ideal de transparencia buscado por Martínez.

Palabras claves: Juan Luis Martínez, lenguaje de los pájaros, lenguaje del paraíso, mística.

\section{ABSTRACT}

In this article I track some of the sources enunciated by Juan Luis Martínez in two texts from La nueva novela, and I relate them with other musicians and poets who share the obsession for birds. Then I analize the topic of the language of paradise, which reflects the ideal of transparency sought by Martínez.

Keywords: Juan Luis Martínez, language of the birds, language of paradise, mysticism.

Recibido: 28-07-2009. Aceptado: 23-09-2009.

* Este artículo forma parte de mi proyecto de investigación "La mística en los límites de la poesía contemporánea" (Proyecto Fondecyt de Iniciación a la Investigación 11080248, 2008-2011). $\mathrm{Su}$ origen es una investigación previa, realizada para el concierto "Lengua de Pájaros. Confabulaciones de música y poesía", a cargo de La Compañía de Céfiro (formado por Sergio Candia, Elke Zeiner, Carmen Troncoso y Felipe Cussen), en el que se intercalan composiciones para flauta dulce inspiradas en el canto de los pájaros y grabaciones de poemas en torno al mismo tema. Este programa fue estrenado el año 2007, y en el año 2009 ha sido editado por el sello SVR gracias al apoyo del Fondo de la Música del Consejo Nacional de la Cultura y las Artes. Para dicho disco he escrito unas notas tituladas "Pájaros, música y poesía", relacionadas con la presente reflexión. 
Estos retazos bastarán, creemos, para evidenciar cuánto yerran quienes se burlan de los relatos en los que se habla del "lenguaje de los pájaros". Ciertamente es muy fácil y harto simple tachar con desdén de "superstición" todo aquello que no se comprende

René Guénon

- $\mathrm{n}$ uno de sus poemas más conocidos, Juan Luis Martínez define el pajarístico como "una lengua transparente y sin palabras" (1985: 89). Este concepto surge dentro de un marco referencial extremadamente cargado y movedizo (así lo advierten Enrique Lihn y Pedro Lastra en sus Señales de ruta de Juan Luis Martinez), envuelto por la ironía y el humor, lo que hace muy difícil que podamos considerar cualquier explicación suya como seria y rotunda. Aunque perfectamente podríamos despacharla como otro caso de parodia academicista dentro de esta obra, me propongo indagar más profundamente en su contenido a fin de interpretar algunas de sus ramificaciones.

De partida, el término surge bajo un título algo rimbombante: "OBSERVACIONES RELACIONADAS CON LA EXUBERANTE ACTIVIDAD DE LA 'CONFABULACION FONETICA' O 'LENGUAJE DE LOS PAJAROS' EN LAS OBRAS DE J. P. BRISSET, R. ROUSSEL, M. DUCHAMP Y OTROS” (1985: 89). Desde aquí podemos tender una primera línea de relaciones, ya que se alude a una serie de autores cuyas escrituras se caracterizan por la obsesión con los juegos lingüísticos. Si comenzamos por los "otros" que no se mencionan, cabría mencionar a algunos que marcan su presencia a lo largo de La nueva novela, como Ferdinand de Saussure (por sus investigaciones sobre los anagramas), Stéphane Mallarmé (particularmente por Les mots anglais), junto a Jean Tardieu, Lewis Carroll y Edward Lear por la inspiración que reciben de las rimas infantiles. Este lenguaje en constante mutación podría asimilarse incluso a las continuas referencias a la poesía china en La nueva novela, como plantea Marcela Labraña (1999), ligándolo a procedimientos como los palíndromos, acrósticos y caligramas (3). Duchamp merece ser aludido por los frecuentes juegos de palabras en sus escritos, y en títulos como "L.H.O.O.Q." para su Gioconda con barba, cuyas letras pronunciadas en francés suenan "Elle a chaud au cul" ("tiene calor en el culo") (Mink, 
2004: 63) o su transmutación en "Rrose Sélavy", que también se escucha como "Eros c'est la vie" ("Eros, eso es vida") (71). Por su parte, toda la obra de Raymond Roussel podría considerarse como una máquina productora de listas, rimas, variaciones y malentendidos. El espacio que permite esta proliferación es la distancia abierta entre las palabras y las cosas, como plantea Michel Foucault (2006) a propósito de Nouvelles impressions: "El vacío descubierto entre máscara y rostro, entre apariencia y realidad, hasta en el espesor ambiguo de las palabras, ese vacío que había que cubrir con tantas figuras fantásticas y meticulosas, se revela como un hervidero de riquezas en mostacilla” (2006: 173).

Jean-Pierre Brisset nos resulta bastante menos conocido, aunque quizás bastaría presentarlo como un personaje igualmente excéntrico que el Professeur Froeppel creado por Tardieu, cuyos problemas se propone resolver Martínez. En sus tratados (La science de Dieu, de 1900, y su posterior edición, Les origines humaines, de 1913) estudia concienzudamente distintas homofonías, pero en vez de potenciar su carácter absurdo o lúdico, da rienda suelta a sus ambiciosas especulaciones filosóficas y metafísicas. Su propósito es encontrar el origen común que tendrían los vocablos que comparten una misma sonoridad, llevando el estudio etimológico hasta la esencia misma del Verbo creador. Así lo afirma en una cita recogida por André Breton (1991) en su Antología del humor negro: "La palabra que es Dios ha conservado en sus pliegues la historia del género humano desde los primeros días, y en cada idioma la historia del pueblo respectivo, con una seguridad y una irrefutabilidad que confundirá tanto a ignorantes como a sabios" (1991: 204). Breton, además, reafirma exactamente la misma ligazón que propone Martínez en su título: "Es sorprendente que la obra de Raymond Roussel y la obra literaria de Marcel Duchamp, se hayan producido, a sabiendas o no, en conexión estrecha con la de Brisset" e indica su influencia sobre "recientes ensayos de dislocación poética del lenguaje" (1991: 206), como los de Desnos, Leiris, Michaux y Joyce, entre otros. Quizás este tipo de modelos (además, evidentemente, del "glíglico" de Julio Cortázar) serían los que tendría en cuenta nuestro autor para componer los versos que ofrece para comentar en sus "Tareas de poesía": "Tristuraban las agras sus temorios / Los lirosos durían tiestamente" (1985: 95).

De cualquier modo, en todos estos casos, más que asociar el pajarístico a una lengua transparente o silenciosa, nos viene a la mente un lenguaje en perpetua ebullición, la confabulación fonética también mencionada en el título que comentamos. La relación entre estos términos contrapuestos se 
explica en la nota asociada a este texto ("NOTA 5. OBSERVACIONES SOBRE EL LENGUAJE DE LOS PÁJAROS”), donde se detalla la relación entre ambos términos: "El Lenguaje de los Pájaros o Confabulación Fonética es un lenguaje inarticulado por medio del cual casi todos los pájaros y algunos escritores se expresan de la manera más irracional posible, es decir a través del silencio. La Confabulación Fonética no es sino la otra cara del silencio" (126). Eso es lo que hace de ésta una comunicación fallida en términos prácticos: "A través de su canto los pájaros / comunican una comunicación / en la que dicen que no dicen nada" (89). Además del carácter inútil de este tipo de lenguaje (en el que insiste Óscar Galindo (2000) en su detallado análisis), vale la pena mencionar una interesante filiación de este concepto propuesta por Marcelo Novoa (2004):

hay un libro de Pablo De Rokha, Ecuación, es de los años 30, allí explica su estética por medio de aforismos y dice '¿qué canta el pájaro?, el pájaro sólo canta lo que se escucha del canto del pájaro, por tanto lo que nosotros oímos no es el canto del pájaro sino que, etc.', que sería una tautología, un recurso expresivo que Juan Luis transformó en pajarístico, entendió lo que quería decir De Rokha y lo continuó (Novoa: 2004).

Esta autosuficiencia coincide con la lectura de Lihn y Lastra: "Entendemos este poema como una poética referida a todas las artes cuyo lenguaje no es literalmente descifrable: la pintura, la música, la poesía misma, pues lo que dice el poema está en lo que convoca el lenguaje (discurso retórico) y no en su lectura referencial" (1987: 16). Como se observa, el recurso al lenguaje de los pájaros trasciende el simple interés por una descripción naturalista o un catálogo de especies, y se transforma en una alegoría del lenguaje artístico, en el que los signos, ya sea por su superposición o su vaciamiento, no pueden denotar nada más que a sí mismos y parecen condenados a su propia negación.

En la página 88, contigua a las "OBSERVACIONES...”, una ilustración nos ofrece otra vía de acceso al mismo tema: se trata de una partitura tomada de Musurgia Universalis ${ }^{l}$ publicado en 1650 por Atanasius Kircher, quien transcribe los sonidos de distintos pájaros, haciendo factible una posible reproducción con voces o instrumentos. Ésta es sólo una pieza más dentro de una larga tradición en la historia de la música que invita a emular a las aves, abarcando desde conocidos conciertos como "Il Gardellino" de An-

\footnotetext{
${ }^{1}$ Agradezco a Matías Ayala por esta referencia.
} 
tonio Vivaldi hasta obras del ornitólogo Olivier Messiaen, entre otros. Ese potencial onomatopéyico, en el que el desarrollo melódico se supedita a la imitación, también se observa con mucha claridad en una obra vocal como "Le chant des oiseaux" de Clément Janequin, en el que la mayoría de las palabras son escogidas en función de su sonoridad, y que en momentos de algarabía polifónica se convierte en un virtual poema sonoro. Ezra Pound (1991) incluyó (de un modo muy parecido a Martínez) la partitura de un arreglo para violín de esta obra junto a su Canto LXXV, y comentaba: "I think Janequin inherited from the troubadours the fine clear cut representation of natural sound, the exactitude of birds and flowers" (en Byron, 2002: 160). No cabe duda que esta comparación es acertada, si recordamos lo que el mismo Pound señalaba acerca de Arnaut Daniel: "he made the birds sing IN HIS WORDS; I don't mean that he merely referred to birds singing”, y escuchamos el propósito de estos versos del trovador:
Doutz braitz e critz
e chans e sos e voutas
aug dels auzelhs qu'en lor lati fan precx
quecx ab sapar, atressi cum nos fam
ab las amiguas en cui entendem² (Daniel, 1994: 76-77).

Aquí no sólo es notorio el intento por colorear sus palabras, particularmente en los graznidos (con los sonidos "tz") del primer verso, sino que volvemos a encontrar (como ya se veía en la "NOTA 5") la asimilación de la figura del poeta con la del pájaro.

Dentro de la poesía del siglo XX esta inspiración se repite con frecuencia, particularmente en sus vertientes más experimentales, en las que la materialidad del lenguaje es exacerbada a costa de la inteligibilidad de su mensaje. El poeta sonoro inglés Bob Cobbing lo proponía explícitamente: "WE ASPIRE TO BIRD SONG” (Cobbing y Mayer, 1978: 43), y seguramente habrá tenido en mente a sus destacados predecesores dadaístas que tendían a la onomatopeya, como Raoul Hausmann en su "Oiseautal": "Pitsu puit puittituttsu uttititi ittitaan / oièt pièt pieteit tenteit tuu uit / ti ti tinax troi troi toi to / liti iti loi loi loioutiouto!" (2007: 125) y Kurt Schwitters en este "Supertrino":

2 "Oigo dulces gorjeos, gritos, cantos, sones y vueltas de los pájaros que hacen plegarias en su latín, cada uno con su pareja, así como hacemos nosotros con las amigas de quienes estamos enamorados" (traducción de Martín de Riquer). 
Ii

Uü

Aa

P'gikk

P'p'gikk (2001: 61).

En el ámbito de la poesía visual, el checo Jirí Kolár presenta ejemplos igualmente interesantes. No tengo la certeza de que Juan Luis Martínez los haya conocido, pero sin duda le hubieran interesado particularmente dos poemas que recuerdan la partitura de Kircher: su "Oiseau chanteur" (205), un collage donde el cuerpo de un ave se forma a partir del recorte de una partitura medieval, y "Le rossignol de Rimbaud" (216), que como explica Vladimir Burda está compuesto "à partir de transcriptions baroques du cant $\mathrm{du}$ rossignol dont les voyelles sont remplacées, suivant la recette rimbaldienne, par des points colorés" (en Kolár, 1988: 227). Esta última también hubiera atraído a nuestro autor por la referencia a Rimbaud, uno de sus fetiches en La nueva novela, y protagonista de uno de sus collages, "Campo de cerezas" (en Nordenflycht, 2001, ilustración No 12), en el que su foto está montada junto a la de un ave doméstica, probablemente un canario ${ }^{3}, \mathrm{y}$ una ventana.

Otro caso significativo, y más cercano, en el que esa alianza se resuelve mediante exploraciones sonoras es Altazor de Vicente Huidobro (1991). Su voz empieza a mutar a finales del canto IV:

El pájaro traladí canta en las ramas de mi cerebro

Porque encontró la clave del eterfinifrete

Rotundo como el unipacio y el espaverso

Uiu uiui

Tralalí tralalá

Aia ai ai aaia i i (1991: 74).

Para disgregarse por completo en el canto $\mathrm{VII}^{4}$. Aunque para algunos se trate de estertores agónicos o un simple caos, este último canto puede representar, como plantea George Yúdice (1978: 206-207), una vuelta a un estado adánico. La experiencia de las vanguardias, en efecto, corrobora los

\footnotetext{
${ }^{3}$ Otros dos collages en los que aparecen pájaros también involucran aves cantoras: "Jaula con rejilla de alambre y gallo pegado a la pared del fondo" (il. no 7) y "Canarios" (il. no 20).

${ }^{4}$ Este canto fue musicalizado por Patricio Wang, del grupo Quilapayún, bajo el título "Dialecto de pájaros".
} 
diversos intereses por promover la reconstrucción o la emergencia de este lenguaje, según opina Jon Erickson (1986) respecto a la poesía sonora de dadaístas y futuristas: "behind this language of presence is the tacit assumption that it is the original, adamic tongue, an ursprache that names an object or being in its essence, which means the signifier is one with the signified and their relationship is not arbitrarily fixed" (1986: 280). De modo más amplio, como plantea Adrian Marino, esto se encontraría en el programa de muchos vanguardistas:

on désire recouvrer l'essence 'magique', voire 'paradisiaque', du langage; on tend à un état de grâce, à une 'renaissance' du verbe qui en restaurerait la pureté absolue. (...) L'avant-garde refait, sur ce chapitre, une expérience primordiale: la réintégration du jardin d'Eden perdu à l'aube des temps, quand l'homme, initié aux mystères, parlait un langage 'secret', capable de communication extatique avec les animaux et les oiseaux (en Weisgerber, 1986: 743).

$\mathrm{Y}$ un relevante poeta sonoro posterior a las vanguardias, Isidore Isou (1947), también propondría al letrismo como "la langue primordiale, primitive et originelle d'où toutes les autres langues se sont extraites" (175).

Este mismo afán puede encontrarse también en experiencias más inocentes; las conocidas jitanjáforas de Mariano Brull nacen, según relata Alfonso Reyes, cuando invitó a su hija "a gorjear, llena de despejo, este verdadero trino de ave: Filiflama alabe cundre / ala olalúnea alífera / alveolea jitanjáforas/ liris salumba salífera // Olivia oleo olorife / alalai cánfora sandra / milingítara girófora / zumbra ulalindre calandra" (1961: 166). La conclusión de Reyes tiende a la universalidad: "Todos, a sabiendas o no, llevamos una jitanjáfora escondida como alondra en el pecho" (1961: 166).

Entramos así a otra zona de significaciones latente en el pajarístico de Juan Luis Martínez, quien al llamarlo igualmente "lenguaje de los pájaros" no ignoraría las resonancias de este término en el saber tradicional. Dentro de este ámbito, el tópico es bastante amplio; no sólo se trata de la ya mencionada capacidad del hombre para comunicarse con los animales y darles un nombre en el paraíso, así como de la idea de "una lengua común primitiva, que ha sido llamada 'idioma de los pájaros" (Cirlot, 1998: 256), sino que también se relaciona con la posibilidad de una comunicación más alta, ligada al estatus de los pájaros como mensajeros celestes, que muchas veces simbolizan el vuelo del alma. Así se observa en la tradición del Corán, donde la señal que indica que se ha alcanzado esa 
comunicación es el momento en que se entiende el lenguaje de los pájaros (Valente, 2008: 515), como lo muestra este fragmento de un hermoso poema del místico sufí Rumi:

“¡Oh corazón!”, dije, “¡bendito seas por haber entrado al círculo de los amantes, por mirar más allá del campo del ojo, por penetrar las sinuosidades del pecho!

¿Cómo es que esta respiración llegó hasta ti, oh alma mía, cómo esta palpitación, oh corazón mío?

Oh pájaro, habla el lenguaje de los pájaros; yo puedo entender tu oculto significado" (1997: 105).

Lo mismo se puede observar en otras culturas: Juan Eduardo Cirlot (1998) menciona la leyenda de Sigfrido, "que empieza a entender el idioma de los pájaros (mensajeros celestes) al llevarse a la boca la sangre del dragón vencido" (256), Jean Chevalier (2003) indica que "los hopi atribuyen también a las aves el poder mágico de comunicarse con los dioses" (156), y Mircea Eliade (1976) lo amplía a las experiencias chamánicas: "Aprender el lenguaje de los animales, y en primer lugar el de las aves, equivale, en cualquier parte del mundo, a conocer los secretos de la naturaleza y, por tanto, a poder profetizar" (94), y constituye uno de los signos de que el chamán "ha reintegrado la situación 'paradisíaca' perdida en el albor de los tiempos" (1976: 95). René Guénon (1995) recuerda algunos de estos ejemplos, y los liga a la experiencia de recitaciones continuas para alcanzar estados superiores, como en los himnos védicos, el esoterismo islámico y los mantra hindúes. La manifestación humana de este lenguaje de pájaros, entonces, no es el habla cotidiana, y es por ese motivo que los libros sagrados se escriben en un lenguaje rítmico, es decir, poético (1995: 49), el que Fulcanelli (1975) describe como "un idioma fonético basado únicamente en la asonancia" (107). De este lenguaje incomprensible y a la vez comprensible nos habla también Cyrano de Bergerac (1992) en su encuentro con un hombrecillo que "me habló en una lengua que yo jamás había oído, y que no tiene nada en común con ninguna de este mundo, y la cual comprendí, sin embargo, con más rapidez y claridad que la de mi propia nodriza" (151). Esta lengua, que Cyrano asocia a la paradisíaca, sería para ese hombrecillo el lenguaje subyacente de la naturaleza: "No sólo es necesaria para expresar todo lo que el espíritu concibe, sino que sin ella no es posible hacernos entender por todos. Como este idioma es el instinto o la voz de la naturaleza, debe ser inteligible a todo lo que vive bajo su dominio" (1992: 151-52). La interrela- 
ción entre los distintos planos de la realidad y del espíritu mediante un tipo especial de lenguaje representa, en consonancia con Brisset, la esperanza del conocimiento superior que vislumbra Walter Benjamin:

El lenguaje de la naturaleza puede compararse a una solución secreta que cada puesto transmite en su propio lenguaje al puesto próximo; el contenido de la solución siendo el propio lenguaje del puesto. Cada lenguaje relativamente más elevado es una traducción del inferior, hasta que la palabra de Dios se despliega en la última claridad, la unidad de este movimiento lingüístico (Benjamin, 1998: 73-74).

Quizás parezca que nos hemos alejado demasiado, pero sólo considerando las variaciones podremos calibrar cómo Juan Luis Martínez se acerca y se distancia de este concepto. Aunque se plantea la posibilidad de descubrir ese engranaje secreto: "Develar el significado último del canto de los pájaros equivaldría al desciframiento de una fórmula enigmática: la eternidad incesantemente recompuesta de un jeroglífico perfecto, en el que el hombre jugaría a revelarse y a esconderse a sí mismo: casi el Libro de Mallarmé" (1985: 126), éste parece un objetivo inalcanzable dentro de la maraña que envuelve no sólo esta obra sino su contexto. Como le cuenta a María Ester Roblero, "Soy un poeta apocalíptico. Creo en el fin de una época. Se perdió la imagen sólida del mundo. Los conocimientos acumulados sólo han servido para la confusión. Nuestra confianza en el lenguaje también se ha perdido. ¡Cosa terrible!" (Martínez, 2003: 67). De esto parecieran tener responsabilidad los poetas: "Los pájaros no ignoran que muchos poetas jóvenes torturan las palabras para que ellas den la impresión de profundidad. Se concluye que la literatura sólo sirve para engañar a pobres gentes respecto a una profundidad que no es tal" (1985: 126). Podríamos encontrar una coincidencia con el siguiente alegato de Guénon (1995): "La poesía no era originariamente esa vana 'literatura' en que se ha convertido por una degradación cuya explicación ha de buscarse en la marcha decadente del ciclo humano" (49). Pero creo, en cambio, que lo que Martínez rechaza no es necesariamente la tortura de las palabras (de la que los versos de "Tareas de poesía" podrían ser un ejemplo tanto como los demás miembros de la "confabulación fonética"), sino la pretensión de ofrecer, o intentar buscar allí, un sentido inexistente. Frente a una actitud conservadora, que intentaría sostener y reparar los vestigios, él superpone y confunde los saberes de nuestra modernidad, para acelerar el final de este ciclo y apurar la llegada del próximo. Así lo entiende Jaime Valdivieso: 
Tal vez el sentido último de este libro sea su capacidad de provocar luminosos sin sentidos, el de desafiar al lector para que compruebe que la racionalidad habitual puede negarse a sí misma y abrir otros espacios y posibilidades al pensamiento (...) Y sobre todo, tomar conciencia que cada ciertos ciclos se hace necesario cuestionar los cimientos sobre los cuales descansa toda nuestra cultura (Valdivieso, 2001: 61).

Y también lo encarnan las apuradas y contradictorias sobreexplicaciones, y en particular los sucesivos desvíos y derivaciones de la "NOTA 5". En el momento en que la cultura y el lenguaje se desmoronan, se derrumba esa realidad fundada precisamente en las palabras. Así, el rol de ese lenguaje de pájaros con resonancias místicas que actuaba como el sistema circulatorio de la naturaleza es definitivamente reemplazado por el silencio:

Para la naturaleza no es el canto de los pájaros ni su equivalente, la palabra humana, sino el silencio, el que convertido en mensaje tiene por objeto establecer, prolongar o interrumpir la comunicación para verificar si el circuito funciona y si realmente los pájaros se comunican entre ellos a través de los oídos de los hombres y sin que éstos se den cuenta (1985: 89).

¿Qué queda, entonces? Según me ha informado Roberto Merino, aunque Martínez poseía el Diccionario de símbolos de Cirlot, decía que no quería aprenderlos, pues suponía que en una obra la actividad simbólica funcionaba involuntariamente. Por eso, a diferencia de Benjamin (y de la tradición que he referido), no habría que tomar las manifestaciones de la naturaleza como punto de partida para un camino de conocimiento más alto, sino más bien emprender el camino de vuelta. Ésa es la desembocadura ineludible de la confabulación fonética, que hacia el final de la "NOTA 5" comienza a retroceder: "Cantando al revés los pájaros desencantan el canto hasta caer en el silencio (...) lenguajeando el silencio en el desmigajamiento de un canto ya sin canto" (1985: 126).

Si los seguimos, y recordamos el método de retrogradación propuesto por Brisset, la palabra original a la que remitirían todos los lenguajes históricos debería ser ese silencio, esa nada. Y creo, a fin de cuentas, que ése es el objetivo final de las operaciones de Martínez, al menos en este par de textos que he comentado: no hay que conocer, memorizar y utilizar los símbolos, 
ni siquiera hay que intentar descifrar sus secretos, sino que es preciso vaciarlos. Bajo esa óptica, el aparente dispendio fonético de los poetas sonoros que cité dentro de este linaje pajarístico sería en realidad un ritual, pues lo que hay que aprender del canto de los pájaros no son sus armonías, sino su ininteligibilidad y su propia disolución: su liberación.

¿Qué es lo último que hacen estos pájaros?:

Deconstruyen en silencio el silencio, retroceden de unos árboles a otros: (han perdido el círculo y su centro: quieren cantar en todas partes y no cantan en ninguna): no pueden callar porque no tienen nada que decir y no teniendo nada picotean como último recurso las migajas del nombre del (autor): picotean en su nombre inaudible las sílabas anónimas del indecible Nombre de sí mismos (1985: 126).

En su propio nombre (el rasgo de identidad más afirmativo que cada uno tiene, y que el propio Martínez tachó en la portada de La nueva novela) se borran para que aparezcan otros nombres propios, o aquel Nombre que, volviendo nuevamente a Brisset, abarca todos los nombres. Y ese Nombre, bien lo sabe Martínez, sólo se encontrará mediante una vía que asuma la impotencia de nombrarlo, ya sea porque las palabras faltan: "Llamar a Dios con una palabra es restringirlo. Él está más allá de las palabras"(2003: 66), o sobran: "creo en Dios, que es el nombre que no debe nombrarse" (2003: 72).

\section{REFERENCIAS}

Benjamin, Walter. 1998. Para una critica de la violencia y otros ensayos. Iluminaciones $I V$. Introducción y selección de Eduardo Subirats. Traducción de Roberto Blatt. Madrid: Taurus Ediciones.

Bergerac, Cyrano de. 1992. El otro mundo. Traducción de Luis Zapata y Carlos Bonfil. Edición, prólogo y notas de Marc Cheymol. México: Consejo Nacional para la Cultura y las Artes.

Breton, André (selección y prólogo). 1991. Antología del humor negro. Traducción de Joaquín Jordá. Barcelona: Editorial Anagrama.

Byron, Mark. 2002. "A Defining Moment in Ezra Pound's Cantos". Michael J. Meyer (ed.). Literature and music. New York: Rodopi, pp. 157-182.

Chevalier, Jean (dirección). 2003. Diccionario de los simbolos. Con la colaboración de Alain Gheerbrant. Traducción de Manuel Silvar y Arturo 
Rodríguez. Barcelona: Herder.

Cirlot, Juan Eduardo. 1998. Diccionario de simbolos. 3a edición. Madrid: Ediciones Siruela.

Cobbing, Bob y Peter Mayer. 1978. Concerning Concrete Poetry. London: Writers Forum.

Daniel, Arnaut. Poesías. 1994. Traducción, introducción y notas por Martín de Riquer. Barcelona: Quaderns Crema.

Eliade, Mircea. 1976. El chamanismo y las técnicas arcaicas del éxtasis. Traducción de Ernestina de Champourcin. México DF: Fondo de Cultura Económica.

Erickson, Jon. 1986. "The Language of Presence: Sound Poetry and Artaud”. Boundary 2, Vol. 14, N 1/2, Autumn, 1985 / Winter, 1986, pp. 279-90.

Foucault, Michel. 2006. Raymond Roussel. Traducción de Patricio Canto. México DF: Siglo XXI Editores.

Fulcanelli. 1975. Las moradas filosofales. Traducción de Vicente Villacampa. Barcelona: Plaza \& Janés Editores.

Galindo, Óscar. 2000. "El Alfabestiario universal de 'La nueva novela' de Juan Luis Martínez”. Revista Chilena de Literatura 57, pp. 21-40.

Guénon, René. 1995. Simbolos fundamentales de la ciencia sagrada. Traducción de José Luis Tejada y Jeremías Lera. Barcelona: Paidós.

Hausmann, Raoul. 2007. Une anthologie poétique précédé de $R H$ l'optophonétiste par Isabelle Maunet-Salliet. Marseille: Éditions Al Dante.

Huidobro, Vicente. Altazor. 1991. Edición facsimilar. Prólogo de Óscar Hahn. Santiago: Editorial Universitaria.

Isou, Isidore. 1947. Introduction a une nouvelle poésie et a une nouvelle musique. 2e édition. Paris: Éditions Gallimard.

Kolár, Jirí. 1988. Poèmes du silence. 1959-1964. Traduit du tchèque par Erika Abrams. Avec une postface de Vladimír Burda. Paris: Éditions de la Différence.

Labraña, Marcela. 1999. "La Nueva Novela de Juan Luis Martínez y la cultura oriental”, en Vértebra 4, pp. 2-6.

Lihn, Enrique y Pedro Lastra. 1987. Señales de ruta de Juan Luis Martínez. Santiago: Ediciones Archivo.

Martínez, Juan Luis. 1985. La nueva novela. Santiago: Ediciones Archivo.

Martínez, Juan Luis. 2003. Poemas del otro. Poemas y diálogos dispersos. Edición de Cristóbal Joannon. Santiago: Ediciones Universidad Diego Portales. 
Mink, Janis. 2004. Duchamp. Traducción de Carlos Caramés. Colonia: Taschen.

Novoa, Marcelo. 2004. "14 piezas sueltas (y un texto de oídas)". [En línea] Disponible en http://www.antiparasitos.cl/01/01-palabreria/01_ novo_14pi.htm. Consulta: 01/07/2007.

Nordenflycht Concha, José de. 2001. El gran solipsismo. Juan Luis Martínez. Obra visual. Valparaíso: Editorial Puntángeles Universidad de Playa Ancha.

Pound, Ezra. 1991. ABC of Reading. Londres: Faber and Faber.

Redferm, Walter. 2001. All puns intended. The verbal creation of Jean-Pierre Brisset. Oxford: Legenda.

Reyes, Alfonso. 1961. La experiencia literaria. Segunda edición. Buenos Aires: Editorial Losada.

Rumi, Yalal al-Din. 1997. Poemas sufies. Versión, selección, prólogo y notas de Alberto Manzano. Madrid: Ediciones Hiperión.

Schwitters, Kurt. 2001. Poesía fonética. Edición de José Antonio Sarmiento. Cuenca: Ediciones de la Universidad de Castilla-La Mancha.

Valdivieso, Jaime. 2001. "Juan Luis Martínez: adiós a la cordura”. En Soledad Fariña y Elvira Hernández (edición). Merodeos en torno a la obra poética de Juan Luis Martinez. Santiago: Ediciones Intemperie, pp. 53-61.

Valente, José Ángel. 2008. "La lengua de los pájaros". En Ensayos. Edición de Andrés Sánchez Robayna. Recopilación e introducción de Claudio Rodríguez Fer. Barcelona: Galaxia Gutenberg / Círculo de Lectores, pp. 514-35.

Weisgerber, Jean (edición). 1986. Les Avant-Gardes Littéraires au XXe Siècle. 2 volúmenes. Budapest: Akadémiai Kiadó.

Yúdice, George. 1978. Vicente Huidobro y la motivación del lenguaje. Buenos Aires: Editorial Galerna. 